\title{
Rehabilitation Issue of Stone Spouts as a Part of an Alternative Source of Public Water Supply Scheme Within Lalitpur Metropolitian City Area
}

\author{
Govinda Prasad Poudel ${ }^{*}, 1$ \\ ${ }^{1}$ Department of Civil Engineering, Thapathali Campus, Institute of Engineering, \\ Tribhuvan University, Kathmandu, Nepal \\ "Corresponding Email: poudelgpd@gmail.com
}

\begin{abstract}
Stone spouts of LMC can be classified according to the water availability. Out of sixty-one stone spouts, only twelve numbers of stone spouts were effectively running up to 2006. These are Manga Hiti, Iku Hiti, Sincha Hiti, Haku Hiti, Konti Hiti, Alko Hiti, Chyasa Hiti, Sundhara, Tapa Hiti(a), Wasa Hiti, Tanga Hiti and Shova Hiti. These stone spouts are considered as good type according to availability of water. Remaining out of fourty- nine stone spouts thirty-four are less effective i.e average type and fifteen are dried up and not exist up to 2006. Comparing different scenarios and results from user's survey in 2006 and 2019 it is found that yield capacity of every stone spout is being reduced every year and also dried up which we consider good type stone spouts like sundhara patan. Out of sixty-one stone spouts more than fourty stone spurts are almost dried up. This shows the immediate restoration requires for preservation of water from stone spouts.
\end{abstract}

Keywords: Lalitpur Metropolitan City (LMC), Nepal Water Supply Corporation (NWSC), Stone Spouts, Users Survey, Water Demand

\section{INTRODUCTION}

The early settlement appears in the valley had started around 7th century BC. Lalitpur metropolitan city (LMC) is the city area under Lalitpur district in Kathmandu valley. In LMC, there are basically two water supply systems to the water demand of its population, i.e. traditional water supply and piped water supply. Patan's large-scale traditional water supply system of network of canals (Rajkulo), which could have connected the city's Hitis (Dhungedhara), wells and ponds from sources at the edge of the valley's floor for continuous supply and recharging, water holes and deep wells (Inara) providing a supplementary layer of hundreds of small-scale water sources for the city, probably from a very early date[1]. According to a record at LMC, there are 61 stone spouts and 25 major ponds in the city, majority 
of which are concentrated in the traditional core area [3]. According to Nepal Water Supply Corporation (NWSC), the modern-day piped water supply system in LMC has two sources at Sainbu reservoir and next Chapagaon reservoir. Sainbu Reservoir is located at Sainbu Bhaisepati at the south of the city. There are two reservoir each capacity $2700 \mathrm{cu}$.m. It collects water from surface runoff from Satmool intake, Sesh Narayan intake and Kuturi intake.It is said to collect ground water through deep tube wells in Pharping during dry season. The total yield is $22 \mathrm{mld}$ in wet season and $16 \mathrm{mld}$ in dry season. It is the main source of bulk of the municipality area. The Chapagaon Reservoir is located at Chapagaon. It has two reservoirs located at Tahakhel-old and new-each has capacity of $500 \mathrm{cu} . \mathrm{m}$. These reservoirs collect water from surface runoff from Naidu khola, Deaki spring, Basuki spring. It also collects water from Muidole pump house and Charghare pumped house [1-3]. The total yield is $10 \mathrm{mld}$ in wet season and $6 \mathrm{mld}$ in dry season. It is also important source of municipal water source. This piped network supplies 32 million liters per day of water in wet season and 22 million liters per day in dry season, while the total demand is greater than 45 million liter per day [5].

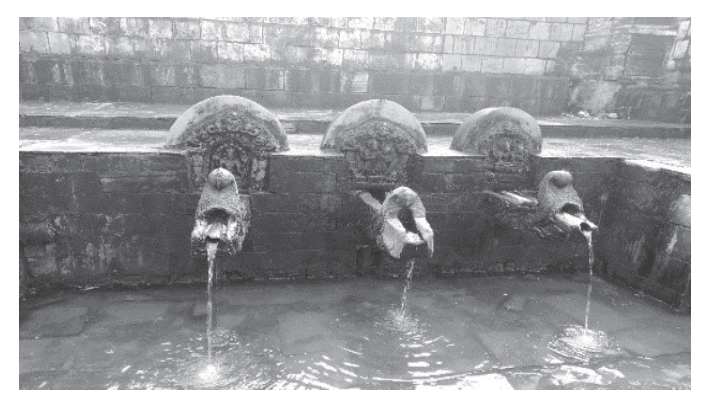

Figure 1: Iku Hiti, Dhobighat

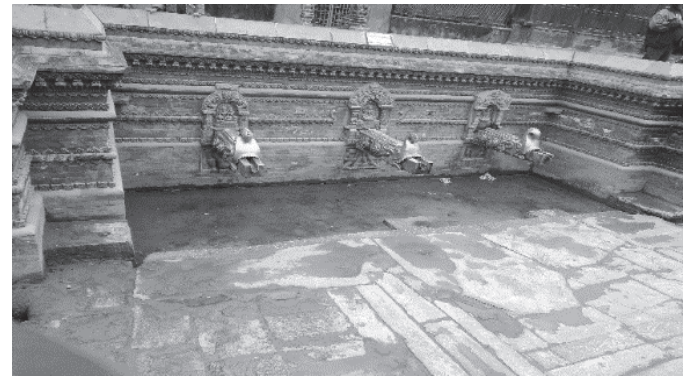

Figure 2: Sundhara, Patan

City water supply system was established by Rana Prime Minister Bir Shumsher in 1895 A.D. by implementing two schemes mainly Tri Bhim Dhara Scheme in the north-west and Bir Dhara Scheme in the north. Under the first and second schemes seven and two surface sources were tapped respectively and water was diverted to a number of collecting points for treatment and short-term storage in service reservoirs before supplying to the people of Kathmandu. Also, in the same year Kharipati Scheme was introduced in Bhaktapur. Doodh Pokhari scheme for Lalitpur was however implemented only in 1904 A.D. [1-4]

Valley water supply system was gradually expanded in 1960 when water from the tailrace of Sundarijal Power Plant was tapped and supplied to the people of Kathmandu after treatment in a treatment plant of 20.50 MLD capacity. To properly address the need of increasing population, HMG in 1973 created a separate entity known as "Water Supply and Sewerage Board". The same Board was later on converted into present Nepal Water Supply Corporation [5].

With the introduction of World Bank Projects (1974 A.D. to 1981 A.D.), valley water supply system was further expanded to many parts of the city by tapping more surface sources like Sat Mools (Seven springs) and Kutori Mools located in the south of the valley and by extracting ground water sources from various part of the valley mainly in the north. With the increase in the population and subsequently in 
the water demand, more deep tube wells were dug and more surface sources were tapped to ease the water supply situation in the valley [5].

Because of the continuous water deficit in the supply system, Melamchi concept was bought into the surface in 1988 A.D. through a pre-feasibility study. The project, which was officially targeted to be completed in 2004, could not be completed in time due to several reasons. HMG has put another target to complete it in 2009 and then 2020, but the concerned officials are still doubtful with regard to new the completion date

\section{STATEMENT OF THE PROBLEM}

When the piped water supply network was introduced in the city (from 2031 B.S.) the traditional sources were not maintained as required. However, the NWSC piped water supply was also not able to meet the rising demand and now the people of Lalitpur are facing a severe water crisis. This has now led to the revival of awareness among people to upkeep of the traditional sources and most people near such stone spouts depend more on these sources than the piped supply.

\section{METHODOLOGY}

To measure the contribution of stone spout, a structured questionnaire was used to interview randomly selected respondents. The stone spout in LMC was categorized into four categories based on the present status of operation and using the information collected from the Key Informant Survey. Among four category one category i.e. stone spouts of dried up and not exists was not involving for users survey due to lack of users. Stone spouts were randomly selected from each category to cover the user's survey. Respondents will be selected by random sampling to ensure that the survey has a representative sample and sufficient statistical validation in explanatory variables such as water source usages, purpose of water usages and socio-economic profiles. The effective sample size is around $10 \%$ of user group in the selected stone spout area.

Data analysis was started after processing field data. Analysis mainly based on the respondents' response.

\section{RESULTS AND DISCUSSION}

Users' survey was conducted in 2006 for four stone spouts. Out of them, Iku Hiti and Patan Sundhara are good type of stone spout. Similarly, Sauga Hiti and Maka Hiti are less effective and and dried up type, respectively.The public water consumption patterns are different for each stone spout. In the case of Iku hiti average per capita water consumption from the stone spout source is $28 \mathrm{lpcd}$, while per capita water consuming from all available sources is $49 \mathrm{lpcd}$. .In case of Patan Sundhara average per capita water used from the stone spout source is $27 \mathrm{lpcd}$ and from all available sources including stone spout source is $30 \mathrm{lpcd}$..Sauga Hiti is less effective type of stone spout and per capita water consumption from the stone spout source is $23 \mathrm{lpcd}$, while total use from all available sources including stone spout is 29 lpcd. In the case of Maka Hiti, average per capita water consumption from stone spout is only 8 lpcd but total per capita consumption from all available sources is 32 lpcd.From the above findings, it can be 
concluded that the public water consumption rate is poor in all cases and do not meet the minimum standards.

Users' survey was conducted in 2019 for four stone spouts. Out of them, Iku Hiti is effectively discharging water up to till date throughout the year which can be seen in figure but Patan Sundhara is not functioning effective. It discharging water effectively only four months (July to October). Remaining eight months sundhara is completely dried up which is shown in figure. Similarly, Sauga Hiti and Maka Hiti both are equivalent to dried up. Maximum consumption rate from stone spout water in LMC area is 20 lpcd in case of good type of stone spout area and minimum of $10 \mathrm{lpcd}$ in case of average type of stone spouts. Socio economic parameters show all categories i.e. both economically strong as well as poor people using stone spouts water.Yield capacity of every stone spout is being reduced every year and more than fourty stone spourts are almost dried up. This shows the immediate restoration for preservation of water from stone spouts.

\section{CONCLUSIONS}

Comparing different scenarios and results from user's survey in 2007 and 2019 it is found that yield capacity of every stone spout is being reduced every year and out of sixty-one stone spouts more than fourty stone spurts are almost dried up. This shows the immediate restoration requires for preservation of water from stone spouts. Especially in core area of LMC there was huge water crises for subsistence of people. Therefore, it is urgent to restoration. The possible restoration of stone spouts flow may be artificial recharge of large no of traditional ponds as well as clearing of inlet and outlet of underground drainages pipes which maintain flow for stone spouts.

\section{ACKNOWLEDGEMENT}

I would like to express my sincere gratitude to Journal publication committee IOE Thapathali Campus, to bring out this publication. I also like to express my gratitude to P.L Joshi, Rudra Adhikari and Rudra Gautam for providing available information's from LMC office.

\section{REFERENCES}

[1] Joshi P.L: Feasibility Study of Rajkulo: Rehabilitation of patan's Traditional Water supply Network, Main Report Volume 1, 1993

[2] Gyawali, D, (2001) water in Nepal, Water Aid Nepal, Kathmandu.

[3] City profile of Lalitpur Sub-Metropolitan city (LSMC), 2005

[4] Integrated Consultant Nepal (P) LTD: "Study of Traditional Spouts" (Dhunge Dhara) in Kathmandu valley, Final Report, 2006.

[5] Poudel, G, (2007) M.Sc. Program in Water Resources Engineering pulchowk campus thesis: "contribution of traditional stone spouts to meet the water demand in the community of Lalitpur sub-metropolitan city area" 